\title{
Ethnic differentials in parental health seeking for childhood illness in Vietnam
}

Bussarawan Teerawichitchainan

Population Council

James F. Phillips

Population Council

Follow this and additional works at: https://knowledgecommons.popcouncil.org/departments_sbsr-pgy

Part of the Community Health and Preventive Medicine Commons, Demography, Population, and Ecology Commons, Family, Life Course, and Society Commons, Health Policy Commons, International Public Health Commons, Maternal and Child Health Commons, Medicine and Health Commons, Public Health Education and Promotion Commons, and the Women's Health Commons How does access to this work benefit you? Let us know!

\section{Recommended Citation}

Teerawichitchainan, Bussarawan and James F. Phillips. 2007. "Ethnic differentials in parental health seeking for childhood illness in Vietnam," Poverty, Gender, and Youth Working Paper no. 3. New York: Population Council. Version of record: https://doi.org/10.1016/j.socscimed.2007.10.020 


\section{POVERTY, GENDER, AND YOUTH}

Ethnic Differentials in Parental Health Seeking for Childhood IIIness in Vietnam

Bussarawan Teerawichitchainan and James F. Phillips 


\section{(2) Population Council}

One Dag Hammarskjold Plaza

New York, New York 10017 USA

www.popcouncil.org pubinfo@popcouncil.org

Our new name Beginning with the first number of 2007, Policy Research Division working papers are now called Poverty, Gender, and Youth working papers. For information on papers in both series, including those that are available for downloading in PDF format, see www.popcouncil.org/publications/wp/index.html

This material may not be reproduced without written permission from the authors.

ISSN: $1554-8538$

(C) 2007 The Population Council, Inc. 


\title{
Ethnic Differentials in Parental Health Seeking for Childhood Illness in Vietnam
}

\author{
Bussarawan Teerawichitchainan
}

James F. Phillips

\begin{abstract}
Bussarawan Teerawichitchainan is Postdoctoral Fellow, Population Council, currently based in Vietnam. James F. Phillips is Senior Associate, Poverty, Gender, and Youth Program, Population Council. This research was funded by grants to the Population Council from an anonymous donor and the Atlantic Philanthropies. We thank Sajeda Amin, Sarah Bales, Charles Hirschman, Jane Hughes, James Knowles, and three anonymous reviewers for their insightful comments on earlier drafts. We gratefully acknowledge Vietnam's Ministry of Health for permission to use the Vietnam National Health Survey.
\end{abstract}




\begin{abstract}
Vietnam's sustained investment in primary healthcare since the onset of socialism has lowered infant and childhood mortality rates and improved life expectancy, exceeding progress achieved in other poor countries with comparable levels of income per capita. The recent introduction of user fees for primary healthcare services has generated concern that economic policies may have adversely affected health-seeking behavior and health outcomes of the poor, particularly among impoverished families who are members of socially marginalized minority groups. This paper examines this debate by analyzing parental recall of illness and care-seeking for sick children under age 5 recorded by the 2001-2 Vietnam National Health Survey. We estimate statistical models of the determinants of parental recall of incidence and response to illness among their children. Ethnic minority parents less frequently reported their children to have been sick than Kinh and Chinese parents. When they recognize an illness episode, minority parents are less likely to seek care-whether professional consultation or self-prescribed carethan non-minority parents. Ethnic differentials are evident in all geographic and income levels, although adverse effects of minority status are most pronounced among poor households in remote areas. Regression estimates of the effects of ethnicity and maternal education on health decisions are pronounced even when poverty effects are controlled, suggesting that social equity may have been under-emphasized in Vietnam's early health policy deliberations. Policies extending free healthcare to poor communes affect parental decisions to seek professional care or self-prescribed care among better-off parents without affecting parental decision making among the poor. Early health initiatives for the poor may therefore have failed to offset equity problems confronting impoverished ethnic minority families.
\end{abstract}


While it is widely documented that parents' social and economic characteristics affect the health and survival of children, less is known about the extent to which ethnic minority status and poverty-reduction policies mediate these effects. Proper care for sick children promotes health improvements and, in turn, has positive effects on children's survival and their development. Since the 1950s, the government of Vietnam has established a vast network of primary health facilities to promote healthcare equity, including comprehensive prenatal care and delivery services, care throughout early childhood, and basic health needs throughout the life course. Evidence suggests that these services have lowered infant and child mortality rates and improved life expectancy at all ages (Bryant, 1998; Ladinsky \& Levine, 1985). For this reason, the introduction of user fees for primary healthcare services is the focus of considerable debate because fees could adversely affect household health-seeking behavior among the poor and lead to inequality in access to healthcare in Vietnam (Guldner, 1995; Toan, Trong, Hojer \& Persson 2002; Witter, 1996; World Bank, 2001). We examine this debate by assessing parents' healthseeking behavior for child illness in the context of Vietnam's changing health policies. Our focus is on care-seeking patterns among ethnic minority parents in remote mountainous areas of Vietnam - a segment of the Vietnamese population that is disproportionately poor.

Health-seeking behavior is a function not only of the availability of health facilities and other sources of healthcare but also of the motivation and ability of individuals to seek medical treatment. This study posits relationships that are consistent with the relevant literature, which demonstrates that healthcare decisions on behalf of young children depend on parents' social and demographic characteristics, the sex of the child, parity, maternal education, household economic status, and parental perception of the severity of childhood illness (Bender, Rivera \& Madonna, 1993; Chen, Huq \& D'Souza, 1981; Colle \& Grossman, 1978; Goldman \& Heuveline, 2000; Kutty, 1989). In addition, we examine the role of ethnicity, which has often been overlooked even in contexts where ethnic minorities represent a sizable proportion of the population. We seek to clarify the role of poverty-reduction policies in contributing to healthseeking decisions that respond to the needs of young children, and we hypothesize that exposure to policies has greater effects among the poor than among the better-off.

Analyses are based on data from the 2001-2 Vietnam National Health Survey (VNHS), the first comprehensive national survey that assessed parental recall of illness among their children under age 5 and determinants of parents' care-seeking once they reported that their children were sick.

\section{BACKGROUND}

Vietnam's sustained investment in primary healthcare has achieved greater reductions in infant and child morbidity and mortality rates than reductions observed in other poor countries with comparable levels of income per capita (Bryant, 1998). However, the shift from a redistributive to a market economy in the late 1980s was accompanied by health-sector reforms that included the imposition of user fees at public health facilities, the legalization of private medical practice, and a liberalization of the pharmaceutical industry (Guldner, 1995). These reforms produced a burgeoning private-sector health system, a rapid expansion of pharmaceutical production and retail businesses (Ha, Berman \& Larson, 2002), and concomitant 
changes in health behaviors such as increased use of pharmaceuticals and self-medication (Okumura, 2002). In the immediate post-reform period, the health sector experienced considerable disruption owing to unregulated growth of the private sector and diminishing resources for the public sector. Evidence indicates that these changes had an adverse impact on the health of the poor (World Bank, 2001).

In response to these problems, the government revised the user fee policy in the mid1990s and launched initiatives to address the health needs of the poor, with particular attention to offsetting economic constraints to healthcare access. Two initiatives of the late 1990s that achieved widespread coverage were Program 135 (P135) and the Hunger Eradication and Poverty Reduction Program (HEPR). HEPR mandated the issuance of health insurance documents eliminating or reducing fees charged to beneficiaries at public facilities, in addition to providing micro-credits, subsidized education, and agricultural extension services (Government of Vietnam, 1998a). Approximately 4 million Vietnamese who were classified as poor benefited from this policy, and HEPR may have modestly increased healthcare use (Cuong, 2004); yet, its impact on the health needs of the poor was limited by insufficient funding to sustain the program in the poorest provinces (Knowles, Ekman \& Huong, 2006).

As of 2002, P135 was implemented in 2,326 communes nationwide, with beneficiary communes selected on the basis of adversity arising from their remoteness, a poverty rate higher than 30 percent, and low agricultural productivity (World Bank, 2004). P135 aimed to improve peasants' livelihoods by focusing on commune-level road construction, electrification, and health facilities. Further, the policy aimed to provide residents of P135 communes with free healthcare at public health facilities (Government of Vietnam, 1998b). However, a source of revenue to cover healthcare provision was not ensured until 2002, when another health initiative (Decision 139) was launched. In its early years P135 focused more on investment in commune health station construction than on provision of free care (S. Bales, personal communication, 4 June 2007), leading to uneven implementation of local policies and uneven access to free care in P135 communes. For example, in 2001, 55 percent of all P135 commune health centers reportedly collected user fees to cover the cost of care (Vietnam Ministry of Health \& General Statistics Office, 2003).

Social inequality arising from minority status may have limited the success of these early health initiatives. Recent evidence indicates that ethnic minorities benefited far less from improvements in Vietnam's living standards than the majority Vietnamese (i.e., Kinh) and Chinese, who together account for 85 percent of Vietnam's 83 million total population. As Figure 1 shows, poverty rates declined significantly for the Kinh and Chinese while remaining constant for ethnic minorities between 1993 and 2002 (Baulch, Chuyen, Haughton \& Haughton, 2004; van de Walle \& Gunewardena, 2001). Evidence suggests that this mounting ethnic economic disparity is attributable not only to the remoteness of minority settlements, but also to a combination of other social factors (Swinkels \& Turk, 2004; World Bank, 2004). Even within the remote mountainous areas, the Kinh experienced greater improvement in living standards than ethnic minorities, suggesting that pro-poor policies targeted to remote regions benefited Kinh residing in these localities more than the ethnic minority populations who were their original target. 
Attempts are underway to improve pro-poor health policies. Decision 139, for example, is intended to finance healthcare expenses for the poor in every province of Vietnam, for residents of P135 communes, and for ethnic minority residents in 12 northern and central highland mountainous provinces. A parallel program was subsequently launched to provide free healthcare for all children under age 6 irrespective of their household economic status. Because Decision 139 was not yet implemented at the time of the 2001-2 VNHS, its efficacy is still under evaluation (Knowles, Ekman \& Huong, 2006).

\section{DATA AND METHODS}

Conducted by the Ministry of Health and the General Statistics Office, the VNHS is a population-based nationally representative sample data set that provides a unique resource for analyzing care-seeking behavior of the parents of young children. Data are derived from a threestage, stratified, cluster random probability sample of 36,000 households containing nearly 160,000 individuals from 1,200 communes nationwide. Owing to a sampling design that produced unequal probabilities of cluster selection, our analysis adjusts for clustering and stratification effects.

Each sample household was visited twice, with the second visit taking place approximately four weeks after the first. During the first visit, interviewers prepared household key informants to record in a diary any illnesses lasting more than 24 hours for every household member who became sick in the following four weeks. Informants were also asked to record information regarding healthcare use and expenditures for each illness. At the second visit, interviewers used the diary to prompt key informants about health problems of household members and to verify types of care and treatment expenses. Past studies indicate that data derived from health interview surveys such as the VNHS are more appropriate for documenting treatment behavior than those based on samples of patients in hospitals or clinics on which many studies of child morbidity in developing countries rely (Kalter, Gray, Black \& Gultiano, 1991). The survey also provides data on household socioeconomic characteristics and commune-level exposure to poverty-reduction programs, thereby providing a basis for estimating the impact of policies on health-seeking behavior and on perceptions of service quality. This study consists of two analyses:

Analysis of illness incidence: The first analysis estimates determinants of illness incidence among 11,355 children under age 5, based on parental retrospective recall of illness episodes. In the VNHS, an illness episode corresponds to reported symptoms that lasted for more than 24 hours during a four-week observation period. In the survey, respiratory infection and diarrhea were distinguished from other childhood illnesses and accounted for 31 and 11 percent respectively of all reported illnesses among under-5 children. Chronic diseases and accidents together accounted for a very small proportion (less than 5 percent). No attempt was made in VNHS to delineate "other acute illnesses," which accounted for over half of all causes of morbidity for young children in the sample. Survey instruments also allow an assessment of illness episodes by parental perception of the severity of illness. The dependent variable in the first analysis is a polytomous variable indicating whether an under-5 child experienced severe, moderate, or slight illness or no illness at all. Forty-five percent of children were not sick during 
the four-week observation period, 28 percent were reported to have been slightly ill, 21 percent moderately ill, and 6 percent severely ill. Most of the children ( 85 percent) who experienced illness had only one episode, and the vast majority of the remaining 15 percent had two episodes of illness. Very few children (less than 1 percent) were reported to have been sick more than twice during the observation period. Because children are the unit of observation in this analysis, one or more episodes recalled by the parents of a given child are assumed to be equivalent indications of both the incidence and perceptions of severity of illness that a child experienced during the one-month reference period.

Analysis of parents' care-seeking for childhood illness: Our second analysis examines corresponding parental health-seeking responses on behalf of 6,134 sample children who experienced at least one illness episode. Parental types of care-seeking are measured as a polytomous categorical variable classifying children who had been ill according to whether their parents sought professional consultation, self-prescribed care, or did not seek any care for one or more episodes of illness occurring to a given child. Self-prescribed care accounted for 56 percent of all parental responses to children experiencing illness, professional consultation accounted for 41 percent, and 3 percent did not seek any care. Parental decisions to self-prescribe included the use of medicines left over from previous family illnesses and the use of self-prescribed medicines purchased at pharmacies. Episodes corresponding to combined self-prescribed care and professional consultation are classified as receiving professional care. When neither of these two types of care was sought, the child is classified as not receiving any care.

Data are analyzed with Stata Release 9. In the first analysis, multinomial (polytomous) logistic regression is employed to test the hypothesis that parental perception of an illness is a function of a child's ethnicity, age, sex, and parity, mother's age, maternal education, household geographic location, and household economic status. The second analysis employs this set of covariates to assess the determinants of parental health-seeking and examines the effects of the perceived severity of child illness and of poverty-reduction policies such as P135 and HEPR. To adjust for intra-familial correlation arising from the shared household experience of multiple children from common households, we correct estimates and errors in both analyses for the within-family effects of parental behavior using the Huber (1967) procedure.

Description of predictor variables: Table 1 presents the distribution of under- 5 children in the sample by each independent variable used in this study. Descriptive statistics are presented for all children and separately for Kinh-Chinese and ethnic minority populations. In addition, results from tests of significance are reported to indicate whether the difference observed between Kinh-Chinese and ethnic minority children for each covariate is statistically significant.

Ethnicity is incorporated in the analyses as a dummy variable indicating whether a child belongs to Kinh-Chinese or ethnic minority populations. In the VNHS sample of under-5 children, Kinh-Chinese comprise approximately 80 percent and ethnic minorities about 20 percent. Ethnic Chinese, accounting for one percent of Vietnam's total population, are combined with Kinh as a category because of the similarity of their social, economic, and cultural characteristics. In contrast, cultural, social, and economic characteristics significantly differentiate other ethnic minorities from the majority Vietnamese (Baulch, Chuyen, Haughton \& Haughton, 2004). Anecdotal evidence suggests that the practice and perception of some ethnic minority groups regarding childbirth and certain diseases such as malaria are different from those 
of the Kinh majority (WHO, 2003). In this study, ethnicity is hypothesized to influence parental reporting of illness incidence and parental responses when illness occurs (Population Council, 1999).

Boys account for 51 percent and girls 49 percent of all under-5 children in the sample. Son preference remains strong in Vietnam, particularly in rural areas (Bélanger, 2002). We expect, therefore, that the child's sex may foster bias in parental recall of childhood illnesses. We hypothesize that when boys become sick, their illness is more likely to be recalled and to be treated by medical professionals than in the case of girls. Infants account for 18 percent of the sample, and infancy (under age 1) is incorporated as a dummy variable. Because children are more vulnerable during their first year of life than in subsequent years, infants may receive more attention from their parents and more investment in healthcare than older children. We find no statistically significant difference in age and sex between Kinh-Chinese and ethnic minority children.

The analyses employ a dummy variable indicating whether a child has three or more surviving siblings (including himself/herself) to adjust for the possible effect of family size on parental recall of illness episodes and health-seeking behavior. Vietnam's total fertility rate has declined to the replacement level (2.11 in 2005). However, rates vary greatly by ethnic groupsranging from 1.87 among the Kinh to 3.2 among the Dao and 7.1 among the Hmong (Vietnam General Statistics Office, 2001). The number of siblings covaries with parental socioeconomic status and household resource demands, both of which are thought to influence parental decisions regarding healthcare for their children. We hypothesize that competition with other siblings for parental resources and time increases directly with the number of siblings. This relationship may be offset, however, if parents who have many children gain experience with childcare that enables them to know when an illness is serious enough to require professional care and when it is a minor ailment that can be cured by self-medication. The number of surviving children, therefore, may affect whether parents recall incidence of their children's illnesses and whether and which type of care was sought. Because of lower fertility rates among Kinh-Chinese, ethnic minority children tend to come from significantly larger families. Nearly half of young minority children had three or more siblings, compared to only one fourth among Kinh-Chinese.

Maternal age and education reflect mother's knowledge related to childcare, which in turn is hypothesized to affect children's incidence of illnesses, type of care selected for sick children, and children's health outcomes. In this study, maternal age is a continuous variable and maternal education is a categorical variable indicating whether the mother was illiterate, had at least some primary education, or had some secondary education. Young mothers, particularly those in their teens, tend to be less experienced in childcare. Although teenage pregnancy is generally uncommon in Vietnam, some ethnic minority women tend to begin childbearing early and continue childbearing throughout their reproductive years (VCPFC \& ORC Macro, 2003). Mean age of mothers of Kinh-Chinese children in the sample was 29.3 years-slightly, yet significantly, higher than that of mothers of ethnic minority children (28.8 years). Although ethnic educational attainment differentials have narrowed in recent years, educational disparities remain large among adults. Nearly half of the sampled ethnic minority mothers were illiterate versus only 7 percent of their Kinh-Chinese counterparts. 
Household characteristics are also incorporated in the analyses to estimate the effect of household accessibility to healthcare facilities and other infrastructure that may affect health, such as access to clean water. Geographic setting is a categorical variable indicating whether a household is located in lowland (including delta, coastal, and midland areas), low mountainous, or high mountainous regions. About 65 percent of children in the sample lived in the lowlands, while 15 and 20 percent resided in low and high mountainous areas respectively. A much higher proportion of ethnic minority children lived in the highlands (72 percent). Compared to young children in the lowlands, we expect children in remote mountainous regions to experience higher incidence of illnesses and lower likelihood of receiving professional care once illness arises. Household economic status is defined by per capita expenditure. In the VNHS, households were stratified into five per capita household expenditure quintiles of equal size defining relative living standards in the population (Bales, 2003). In this study, households in the lowest quintile are classified as poor, while the rest are categorized as less poor. About 29 percent of all under- 5 children in the sample came from poor households. Ethnic minority children disproportionately lived in poverty (77 percent), compared to 18 percent of Kinh-Chinese.

To test the hypothesis that pro-poor policies influence parental health-seeking behavior, a dummy variable is included to indicate whether children lived in households that received a "poor household certificate" or were located in communes where P135 was operative. There are limitations to this measurement. Survey instruments identify parents who used health insurance cards to cover the cost of professional treatment of childhood illnesses, but not parents who had HEPR coverage but did not seek care at a specified time period. Inconsistent implementation of P135 constitutes an additional limitation since the policy aiming to provide free healthcare to all P135 commune residents was not consistently implemented (at least before Decision 139 was launched in 2002). This inconsistency may undermine P135's original objective of increasing healthcare access among the poor. Because household access to P135-mandated free care is not recorded in the VNHS, our investigation assesses the aggregate health impact of exposure to the decree at the commune level rather than the household-level effect of access to free care. We tested the independent effects of HEPR and P135 commune exposure and determined that separate specification of these variables had no effect on results or policy conclusions. Therefore, policy exposure in this study is coded as a composite variable with a value of 1 if a household was exposed to either policy and zero otherwise.

According to Table 1, approximately 23 percent of all children in the sample resided in households that were exposed to early healthcare initiatives under P135 and HEPR. Two thirds of all ethnic minority children lived in communes exposed to these policies, compared to only 13 percent among their Kinh-Chinese counterparts. Mindful of the inconsistency in program implementation and our measurement limitation, we hypothesize that exposure to policies increased the likelihood that parents sought professional consultation in the event of their children's illnesses. Some observers have argued that the more prosperous Kinh residents of P135 communes tend to reap the benefits of Vietnam's pro-poor policies (Swinkels \& Turk, 2004) and that exposure to policies may have a more positive impact on health-seeking behavior of Kinh-Chinese and the less poor than on ethnic minorities and the poor. To test this proposition, we incorporate terms specifying interactions between policy exposure and ethnic minority status, household economic status, and geographic setting. 


\section{RESULTS}

\section{Parental recall of illness incidence among under-5 children}

Figure 2 shows differentials in parental recall of illness episodes among young children by ethnicity and household economic status. For each household wealth category (poor and less poor), a chi-square test of significance is performed to determine whether parental response to perceived morbidity differs between Kinh-Chinese and ethnic minority children.

Among poor households, parental recall of childhood illness incidence was strikingly different between Kinh-Chinese and ethnic minority parents. Significantly higher proportions of non-minority children were reported to have been sick compared to their minority counterparts. Eight percent of Kinh-Chinese children from poor households experienced severe illness, 22 percent moderate illness, and 27 percent slight illness, while about 43 percent of Kinh-Chinese were reported to have had no illness symptoms during the observation period. Higher percentages ( 56 percent) of ethnic minority children were reported as not being sick. Relative to Kinh-Chinese, there were smaller proportions of minority children in every observed level of illness severity.

Among less poor households, there were noteworthy ethnic differentials in parental recall of incidence; yet the differences were less pronounced than those observed among the poor. Although Figure 2 shows slightly higher percentages of ethnic minority children than of KinhChinese children who were reported as not being sick, these differences were not statistically significant. Among Kinh-Chinese, incidence differentials among children from poor versus less poor households were insignificant $\left(\chi^{2}=5.176\right.$, d.f. $=3$, n.s.). This contrasts with the corresponding differentials for ethnic minority children. Incidence among minority children from better-off families was significantly higher than incidence among children of poor families $\left(x^{2}=23.10\right.$, d.f. $=3, \mathrm{p}<0.001)$.

To examine the net effects of ethnicity and household economic status on the incidence of reported child illnesses, we estimate a maximum-likelihood multinomial logistic regression model for assessing the net effect of these covariates controlling for children's sex, age, and parity, maternal age and maternal education, and household geographic location. The determinants of parental recall of illness episodes are assessed by estimating the odds of children being reported to have been slightly ill, moderately ill, and severely ill—relative to the reference category, not being sick. Multivariate odds ratios and robust standard errors are presented in Table 2. The total number of observations is 11,355 children.

Ethnic minority status had a net negative effect on the likelihood of parents' recall of child illness episodes. Results suggest that the effect was strong and consistent for all three levels of perceived severity of illness. Independent of household economic status, household geographic location, and other individual attributes, the odds that minority children would experience slight or moderate illness were about 20 percent less than for their Kinh-Chinese counterparts and nearly 40 percent less for illness perceived to be serious.

As hypothesized, boys were significantly more likely than girls to experience all three levels of episode severity, an association that was most pronounced for severe illness. Children's parity significantly decreased the likelihood of parental recall of illness, regardless of perceived severity. Unlike sex and sibling effects, children's age is not associated with the incidence of 
illness or level of severity. Infants and children were reported to have had equivalent incidences of illness.

Maternal characteristics, particularly mother's education, were significant predictors of childhood illness incidence. The effect of maternal education was salient at all levels of perceived severity of illness. If mothers had some primary schooling, the odds of children being reported as having had a slight illness were 25 percent higher than for children whose mothers were illiterate. The positive effect of maternal education is much more pronounced for children who experienced moderate and severe illnesses than for children reported to have been slightly ill. Regardless of ethnicity and other individual attributes, when mothers had primary or secondary education, children were 59 and 49 percent respectively more likely to be reported as severely ill. When mothers had at least some secondary schooling, the effect of education on the incidence of slight illness was not statistically significant. However, apart from the effect of maternal age on reported slight illness, mother's age was not a statistically significant factor explaining parental recall of illness.

Household characteristics such as geographic setting and economic status were also important indicators affecting incidence of reported illness among young children, but household effects were not as pronounced as expected. Moreover, residing in low and high mountainous regions was associated with 17 and 22 percent decreased odds that children would be reported as moderately ill. Low and high mountainous residence was associated with decreased incidence of reported slight illness but did not have a significant impact on reports of severe illness incidence. The net effect of household economic status on incidence of reported illness was multifaceted. Other characteristics held constant, children from less poor households had greater likelihood of being reported to have experienced slight illness than children from poor households. Yet, children from better-off families had less likelihood of being reported to have experienced serious illness. Household wealth did not explain any differentials in the incidence of reported moderate illness among young children.

Results shown in Figure 2 and Table 2 indicate that regardless of levels of perceived severity, parental recall of illness incidence among under-5 children was significantly lower among ethnic minority children than among the Kinh-Chinese. Ethnic minority children, however, were not necessarily healthier. This relationship would arise if ethnic minority parents seriously underreport childhood morbidity. Geographical analyses consistently show that minority children experience higher risk of severe malnutrition than Kinh-Chinese children (Vietnam Ministry of Health \& General Statistics Office, 2003: Tables B.5.1 and B.5.3). For example, approximately 34 percent and 45 percent of under-5 minority children in northern mountainous and central highland regions are wasted (low weight for age) versus 23 percent among the Kinh-Chinese, In mountainous regions, 41 percent of minority children were stunted (low height for age) versus only 19 percent among the Kinh-Chinese. This well-established link between minority status, malnutrition, and childhood morbidity suggests that reported childhood morbidity is spuriously low among minority parents. Findings suggest that the underreporting of incidence may be particularly pronounced in mountainous areas, where mothers with at least some education were much more likely to report episodes of childhood illness than mothers who were illiterate. This impact of maternal educational attainment prevails among all economic strata and geographic settings. 


\section{Determinants of parental health-seeking behavior for childhood illness}

Figure 3 shows differentials in types of care parents sought for their children once they became sick. The types of care Kinh-Chinese and ethnic minority children received in the event of illness were significantly different. Ethnic differentials in parental care-seeking were statistically significant and pronounced among children of poor households $\left(\chi^{2}=115.87\right.$, d.f. $=2$, $\mathrm{p}<0.001)$ and among children of less poor households $\left(\chi^{2}=33.18\right.$, d.f. $\left.=2, p<0.001\right)$. Among poor households, self-medication was the most common parental health-seeking decision. Over two thirds of all parents of sick Kinh-Chinese children self-prescribed care, while about 58 percent of their minority counterparts did so. Proportions of sick children receiving professional consultation were slightly higher for Kinh-Chinese (32 percent) than minority children (28 percent). The most striking differential is in proportions of children not receiving any care when they experienced illness. Only rarely were Kinh-Chinese children left untreated (1 percent), in contrast to a high proportion of ill minority children who were left untreated (14 percent).

Professional consultation was more common in less poor than in poor households, particularly among Kinh-Chinese. About 45 percent of Kinh-Chinese children from better-off families received medical care from professionals when they were ill. Self-medication, however, remained the most popular parental response to childhood illness. Slightly over half of KinhChinese parents gave their sick children self-prescribed medication. Proportions of minority children who received self-prescribed care were substantially higher among those who were less poor (67 percent) than those who were poor (58 percent). While 14 percent of ill children from poor minority families did not receive any care, only two percent of their counterparts from better-off families experienced unattended illness.

Findings suggest that better-off Kinh-Chinese parents resorted to professional care in the event of child illness, whereas better-off ethnic minority parents were more likely to provide self-prescribed care. Although compelling, this conclusion merits assessment in a maximumlikelihood multinomial logistic regression analysis that adjusts for the potentially confounding inter-correlated effects of ethnicity and household economic status. Table 3 reports multivariate odds ratios based on a multinomial logistic regression analysis of 6,134 observations of sick children classified according to parental decisions to seek professional consultation or selfprescribed care relative to the reference category, not seeking care.

Results indicate that children's age, number of siblings, and maternal education were significant determinants of parental decisions to respond to perception of illness by seeking professional consultation or resorting to self-medication relative to not seeking care. Odds that parents would seek professional treatment relative to not seeking any care when a child over age 1 was sick were 36 percent less than if the child was less than age 1 . Yet, childhood age has no independent effect on whether parents gave self-prescribed care or sought no treatment for sick children. Moreover, results indicate that parents with several children were less likely to seek help when one of their children was sick. The net odds of receiving professional consultation or self-prescribed care relative to not seeking care among children with three or more siblings diminished by 50 percent and 34 percent respectively.

Maternal education is a prominent covariate of health-seeking behavior. Regardless of ethnicity and household context, mother's literacy and primary schooling increased the 
likelihood that sick children were treated by medical professionals or received self-prescribed care by 76 and 62 percent. If mothers had at least some secondary education, the odds that their children would be treated with professional care or receive self-prescribed care were elevated more than twofold. Although parents were more likely to report a son's illness episode, findings provide no evidence of selective care deprivation for daughters. Maternal age had no independent effect on how sick children were treated.

Parental perception of the severity of childhood illness had a strong positive effect on the likelihood of seeking professional care but no independent effect on self-prescribed care. Once parents perceived that an illness episode was moderate or severe, the likelihood that they sought care from professionals was threefold and sevenfold greater than if the illness was perceived as slight. In addition, ethnicity and household geographic setting are important indicators of parental care-seeking in Vietnam. Although remoteness of health facilities might constrain parental decisions to seek professional care regardless of ethnicity, the effect of inaccessibility was more pronounced among ethnic minorities than among Kinh-Chinese. Minority parents in mountainous regions were 85 percent less likely to seek professional care compared with the lowlands minority population. While remote residence did not appear to have an independent effect on the likelihood of self-prescribed care among Kinh-Chinese parents in mountainous regions, it negatively affected the odds of self-prescribed care among minority parents. The odds that minority children in mountainous areas would receive self-prescribed care instead of being left untreated were 76 percent less than for children in the lowlands. This negative influence was not offset when controlling for the effect of policy exposure that aimed to improve healthcare access in remote regions.

This analysis estimates direct and indirect effects of exposure to pro-poor health policies as well as interaction terms for the joint effects of policy exposure with ethnic minority status, household economic status, and geographic setting. We find no direct effect of household economic status or policy exposure on parents' seeking professional consultation relative to not seeking any care. Surprisingly, children from better-off families were about 52 percent less likely to receive self-prescribed care than those from poor economic backgrounds. This may reflect parental choice behavior. The tendency of less poor parents to seek professional intervention may substitute for self-prescribed care.

Economically better-off parents who were exposed to pro-poor policies such as P135 or HEPR were much more likely to seek professional consultation or at least to administer selfprescribed care to their sick children than counterparts from poor households. Regardless of their ethnicity and other attributes, the likelihood that sick children from less poor families who had been exposed to policies received professional or self-prescribed care increased by over 8 and 9 times respectively. The interaction of policy exposure with ethnicity and geographic setting shows negative, yet weak, effects on parental care-seeking patterns. Exposure of Kinh-Chinese parents in remote areas to pro-poor policies had no care-seeking effect. Yet, minority children in mountainous regions who were exposed to the policies appeared less likely to receive selfprescribed care by about 72 percent.

These findings, in conjunction with the effect of household economic status, suggest that health initiatives implemented in Vietnam prior to 2002 may not have achieved their objective of reducing inequality in healthcare access in remote settings. Rather, the free healthcare benefit 
provided by the policies may actually serve the needs of the more prosperous rather than the needs of the poor. This may have been the consequence of inadequate funding for poverty policies prior to 2002 and the inability of provincial authorities to finance the free healthcare provisions of P135 and HEPR (Cuong, 2004; Knowles, Ekman \& Huong, 2006). Moreover, P135 investment in the construction of commune health centers for residents of remote communes may have located facilities in the center of the communes where better-off families lived and thus had greater access to healthcare.

\section{DISCUSSION}

To explore issues arising in policy debates about provision of healthcare to the poor, this study used high-quality data from the VNHS to examine covariates of parental health-seeking behavior for childhood illness. Regardless of severity of illness, Kinh and Chinese parents were more likely to report child illness episodes than minority parents. The ethnic differentials in parental reports were robust to the introduction of statistical controls for individual and household characteristics. This result, which is based on parental recall, contrasts with findings from other research that is based on direct evidence of differentially high and pervasive malnutrition among minority children and a strong link between malnutrition and clinically observed child morbidity. This suggests that lower reported incidence by minority parents may be more indicative of parental inability to recognize and report illness than indicative of lower risk of illness among ethnic minority children.

In addition to ethnicity, a child's sex, number of siblings, and household geographic location are also associated with parental recall of childhood illness. Of these, maternal education is the strongest determinant of reported illnesses of children. At all levels of illness severity, literate mothers and mothers with some education were much more likely to report their children's illness episodes. Such findings attest to the need for further investigation into the social determinants of parental recall of illness, since under-reported incidence could lead to spurious conclusions about the social epidemiology of risk. Findings also attest to the need for survey biomarkers and indicators of nutritional status so that information that is free of recall bias can augment and validate data reported by parents.

Consistent with recent studies of health-seeking behavior among adult populations in Vietnam (Ha, Berman \& Larson, 2002; Toan, Trong, Hojer \& Persson, 2002), our results show that self-prescribed care was the most common response of Kinh-Chinese and minority parents to childhood illness. One of the most striking findings is that a substantial number of minority parents reported that they did not seek any care for their sick children. Results are consistent with the possibility that economic factors remain an important determinant explaining whether parents decide to seek professional consultation or give self-prescribed care to their children and that economic gaps are not offset by exposure to health policies in place at the time of the VNHS. In fact, pro-poor policies that sought to encourage low-income populations to seek medical services by eliminating user fees may have achieved the opposite. The household exposure to these health initiatives increased the likelihood that better-off parents would seek professional care for their sick children, but there is no corresponding evidence that free healthcare provision differentially benefits children from poor families. 
While Vietnam's policy deliberations focus on the economic equity of healthcare access, our findings indicate that social factors related to ethnic minority status play an important role in parental decisions to seek care for a sick child. Parents of ethnic minority children were less likely to report that their children were sick. When they recognized illness episodes, they were less likely to seek care, whether self-prescribed care or professional help. Results indicate that ethnic differentials remained in remote areas and at all income levels. While our study provides no evidence that policy exposure increased social equity, expanding maternal education among ethnic minorities may have had pronounced equity effects. Official emphasis on extending maternal education among minorities may eventually contribute to bridging the health equity gap between Kinh-Chinese and ethnic minorities. Moreover, new policies may have greater effects than strategies in place at the time of the VNHS. Since 2002, the government of Vietnam has launched major targeted health policies to improve healthcare access for the poor, and these policies are soon to be evaluated in national survey research. Until these new policies are evaluated, however, evidence from this study suggests that health policies intended to benefit the children of the poor and most vulnerable have yet to demonstrate equity effects. Household social characteristics remain significant determinants of parental health seeking even when poverty effects are controlled. This suggests that social equity may have been under-emphasized in early health policy deliberations. Our results are consistent with the conclusion that policies for extending free healthcare to poor communes affect parental decisions to seek professional care or self-prescribed care among better-off parents without having corresponding impact on parental decision making among the poor. Policies may therefore be failing to increase access to healthcare among impoverished families of ethnic minorities.

\section{REFERENCES}

Bales, S. (2003). Technical documentation for the Vietnam National Health Survey 2001-2. Hanoi, Vietnam: Vietnam Ministry of Health and Statistics Sweden International Consulting Office.

Baulch, B., Truong, K.C., Haughton, D., \& and Haughton, J. (2004). Ethnic minority development in Vietnam: A socio-economic perspective. In P. Glewwe, N. Agrawal \& D. Dollar (Eds.). Economic Growth, Poverty, and Household Welfare in Vietnam (pp. 273310). Washington, DC: The World Bank.

Bélanger, D. (2002). Son preference in a village in rural North Vietnam. Studies in Family Planning, 33, 321-334.

Bender, D.E., Rivera, T., \& Madonna, D. (1993). Rural origin as a risk factor for maternal and child health in peri-urban Bolivia. Social Science \& Medicine, 37, 1145-1349.

Bryant, J. (1998). Communism, poverty, and demographic change in North Vietnam. Population and Development Review, 24, 235-269. 
Chen, L.C., Huq, E., \& D'Souza, S. (1981). Sex bias in the family allocation of food and health care in rural Bangladesh. Population and Development Review, 7, 55-70.

Colle, A.D., \& Grossman, M. (1978). Determinants of pediatric care utilization. Journal of Human Resources, 13S, 115-151.

Cuong, N.V. (2004). Assessing the coverage and impact of Vietnam's programs for targeted transfers to the poor. Hanoi, Vietnam: The World Bank.

Goldman, N., \& Heuveline, P. (2000). Health-seeking behavior for child illness in Guatemala. Tropical Medicine and International Health, 5, 145-155.

Government of Vietnam. (1998a). Decision No. 133/1998/QD-TTg of July 23, 1998 to Ratify the National Target Program on Hunger Elimination and Poverty Alleviation in the 19982000 Period. Hanoi, Vietnam.

- (1998b). Decision No. 135/1998/QD-TTg of July 31, 1998 to Approve the Program on Socio-economic Development in Mountainous, Deep-lying, and Remote Communes with Special Difficulties. Hanoi, Vietnam.

Guldner, M. (1995). Health care in transition in Vietnam: Equity and sustainability. Health Policy and Planning, 10, 49-62.

Ha, N.H., Berman, P, \& Larson, U. (2002). Household utilization and expenditure on private and public health services in Vietnam. Health Policy and Planning, 17, 61-70.

Huber, P.J. (1967). The behavior of maximum likelihood estimates under non-standard conditions. In Proceedings of the Fifth Berkeley Symposium on Mathematical Statistics and Probability (pp. 221-233). University of California, Berkeley.

Kalter, H.D., Gray, R.H., Black, R.E., \& Gultiano, S.A. (1991). Validation of the diagnosis of childhood morbidity using maternal health interviews. International Journal of Epidemiology, 20, 193-198.

Knowles, J., Ekman, B. \& Huong, D.H. (2006). Proposed framework for assessing the impact of Decision 139: Healthcare Fund for the Poor. Hanoi, Vietnam: Vietnam Ministry of Health and Asian Development Bank.

Kutty, V.R. (1989). Women's education and its influence on attitudes to aspects of child-care in a village community in Kerala. Social Science \& Medicine, 29, 1299-1303.

Ladinsky, J., \& Levine, R. (1985). The organization of health services in Vietnam. Journal of Public Health Policy, 6, 255-268. 
Okumura, J., Wakai, S., \& Umenai, T. (2002). Drug utilization and self-medication in rural communities in Vietnam. Social Science \& Medicine, 54, 1875-1886.

Population Council. (1999). Factors behind low use of public healthcare services among ethnic minority groups in Kontum province: A qualitative analysis. Hanoi, Vietnam.

Swinkels, R., \& Turk, C. (2004). Poverty and remote areas: Evidence from new data and questions for the future. Hanoi, Vietnam: The World Bank.

Toan, N.V., Trong, L.N., Hojer, B., \& Persson, L. (2002). Public health services use in a mountainous area, Vietnam: Implications for health policy. Scandinavian Journal of Public Health, 30, 86-93.

Van de Walle, D., \& Gunewardena, D. (2001). Sources of ethnic inequality in Viet Nam. Journal of Development Economics 65: 177-207.

Vietnam Committee for Population, Family and Children (VCPFC) \& ORC Macro. (2003). Vietnam Demographic and Health Survey 2002. Calverton, Maryland, USA: VCPFC and ORC Macro.

Vietnam General Statistics Office. (2001). Census monograph on marriage, fertility and mortality in Vietnam: Levels, Trends and Differentials. Hanoi, Vietnam: Statistical Publishing House.

Vietnam Ministry of Health \& General Statistics Office. (2003). Results of Vietnam National Health Survey 2001-2. Hanoi, Vietnam: Medical Publishing House.

Witter, S. (1996). Doi Moi and health: The effect of economic reforms on the health system in Vietnam. International Journal of Health Planning and Management, 11, 159-172.

World Bank. (2001). Growing healthy: A review of Vietnam's health sector. Hanoi, Vietnam (Report No.22210-VN).

- (2004). Vietnam Development Report 2004: Poverty. Hanoi, Vietnam.

World Health Organization (WHO). (2003). Health and ethnic minorities in Vietnam. Hanoi, Vietnam. 
Figure 1. Persistent poverty among ethnic minorities in Vietnam, 1993-2002

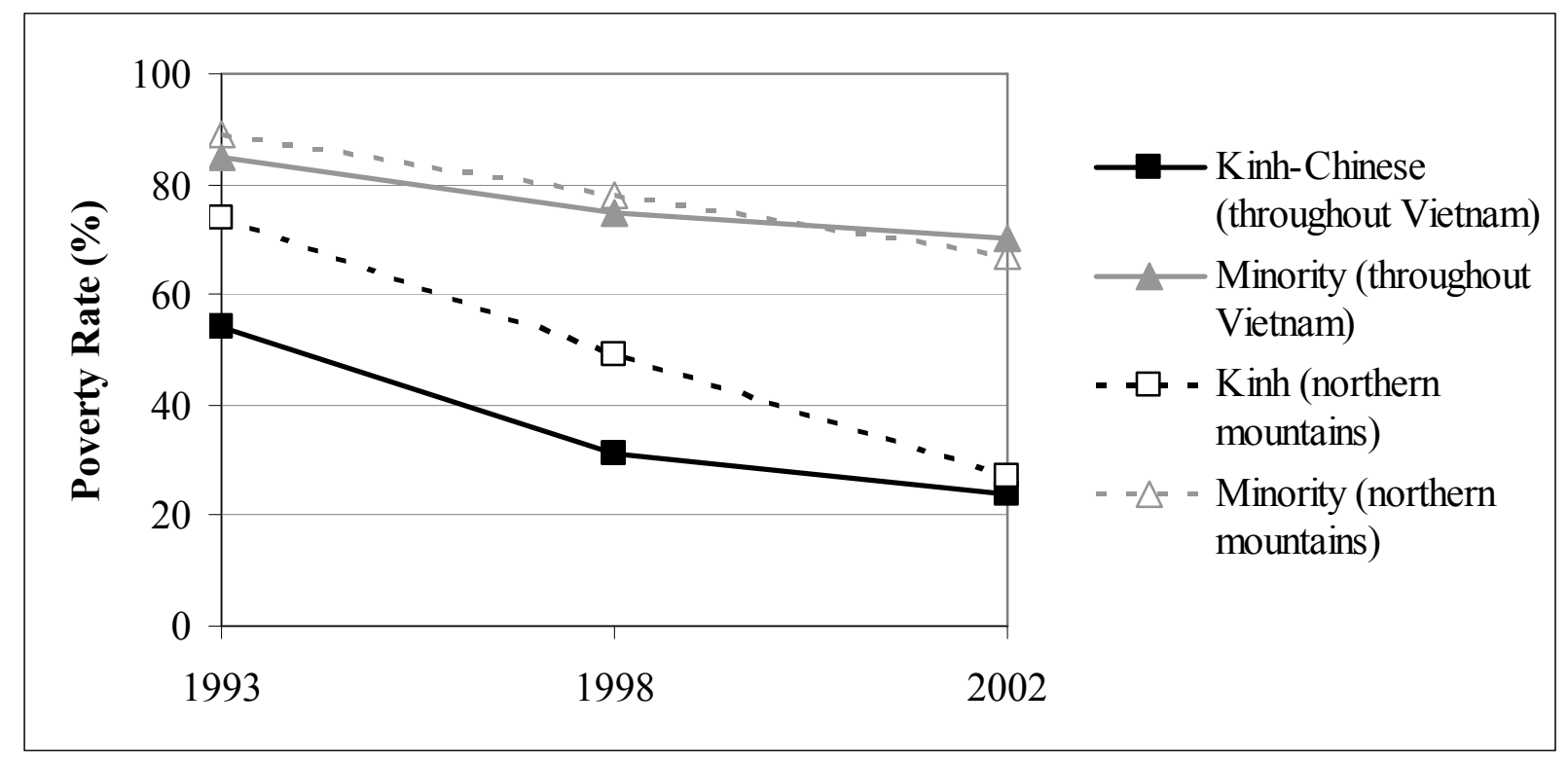

Source: Swinkels and Turk (2004), based on Vietnam Living Standards Surveys 1993 \& 1998 and Vietnam Household Living Standards Survey 2002. 
Table 1. Descriptive statistics, characteristics of children under age 5 in the VNHS sample

\begin{tabular}{|c|c|c|c|c|c|}
\hline \multirow[t]{2}{*}{ Variable description } & $\begin{array}{r}\text { All } \\
(\mathrm{N}=11,355)\end{array}$ & $\begin{array}{r}\begin{array}{r}\text { Kinh- } \\
\text { Chinese }\end{array} \\
(\mathrm{N}=8,991) \\
\end{array}$ & $\begin{array}{r}\begin{array}{r}\text { Ethnic } \\
\text { Minority }\end{array} \\
(\mathbf{N}=\mathbf{2 , 3 6 4 )} \\
\end{array}$ & \multirow[t]{2}{*}{ Sig. } & \multirow[t]{2}{*}{$\begin{array}{c}\text { Chi-square } \\
\text { (d.f.) }\end{array}$} \\
\hline & \multicolumn{3}{|c|}{ Proportion/Mean value } & & \\
\hline \multicolumn{6}{|l|}{ Sex } \\
\hline Boy & 0.51 & 0.51 & 0.51 & n.s. & $0.08(1)$ \\
\hline Girl & 0.49 & 0.49 & 0.49 & & \\
\hline \multicolumn{6}{|l|}{ Age } \\
\hline Under 1 & 0.18 & 0.18 & 0.19 & n.s. & $0.09(1)$ \\
\hline Over 1 & 0.82 & 0.82 & 0.81 & & \\
\hline \multicolumn{6}{|c|}{$\begin{array}{l}\text { Number of surviving siblings including } \\
\text { self }\end{array}$} \\
\hline 2 or fewer & 0.70 & 0.74 & 0.52 & $* *$ & $413.72(1)$ \\
\hline 3 or more & 0.30 & 0.26 & 0.48 & & \\
\hline Mean maternal age (s.d.) & $29.2(6.1)$ & $29.3(5.9)$ & $28.8(6.9)$ & $* *$ & $-6.43^{\mathrm{a}}$ \\
\hline \multicolumn{6}{|c|}{ Maternal educational attainment } \\
\hline Illiterate & 0.14 & 0.07 & 0.49 & $* *$ & $2928.84(2)$ \\
\hline Primary & 0.46 & 0.47 & 0.40 & & \\
\hline Secondary & 0.40 & 0.46 & 0.11 & & \\
\hline \multicolumn{6}{|l|}{ Geographic location } \\
\hline Lowlands & 0.65 & 0.78 & 0.08 & $* *$ & $4781.75(2)$ \\
\hline Low mountainous & 0.15 & 0.14 & 0.20 & & \\
\hline High mountainous & 0.20 & 0.08 & 0.72 & & \\
\hline \multicolumn{6}{|l|}{ Household wealth } \\
\hline Poor & 0.29 & 0.18 & 0.77 & $* *$ & $3248.06(1)$ \\
\hline Less poor & 0.71 & 0.82 & 0.23 & & \\
\hline \multicolumn{6}{|l|}{ Exposure to policies } \\
\hline Yes & 0.23 & 0.13 & 0.67 & $* *$ & $2937.34(1)$ \\
\hline No & 0.77 & 0.87 & 0.33 & & \\
\hline
\end{tabular}

** Difference between Kinh-Chinese and ethnic minority is significant at $\mathrm{p}<0.01$; n.s. $=$ not significant $\mathrm{p}$-value.

${ }^{a}$ Mann-Whitney $\mathrm{z}$ test

Source: VNHS 2001-2. 
Figure 2. Differentials in parental recall of children's illness incidence by ethnicity and household economic status

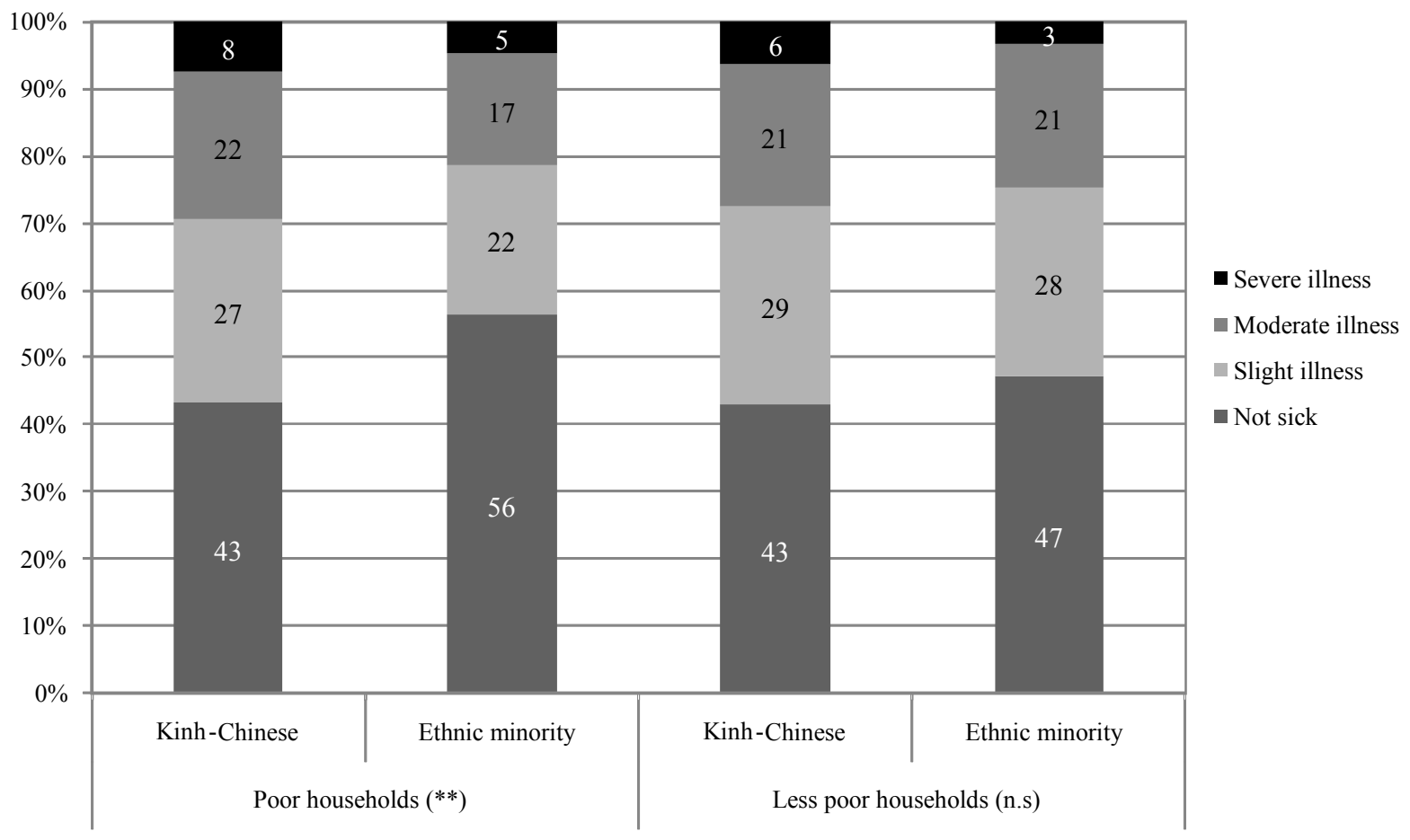

** Difference between Kinh -Chinese and ethnic minority is significant at $\mathrm{p}<0.01 ; \mathrm{n} . \mathrm{s}=$ not significant $\mathrm{p}$-value. Note: Results from chi -square tests of significance are reported in parentheses.

Source: VNHS 2001-2 
Table 2. Maximum-likelihood multinomial logistic regression, incidence of reported illness among children under age 5

\section{Child and household characteristics}

\begin{tabular}{|c|c|c|c|c|c|c|c|c|c|}
\hline Child and household characteristics & $\begin{array}{l}\text { Odds } \\
\text { ratio }\end{array}$ & & $\begin{array}{c}\text { Robust } \\
\text { std. } \\
\text { error }\end{array}$ & $\begin{array}{l}\text { Odds } \\
\text { ratio }\end{array}$ & & $\begin{array}{l}\text { Robust } \\
\text { std. } \\
\text { error }\end{array}$ & $\begin{array}{l}\text { Odds } \\
\text { ratio }\end{array}$ & & $\begin{array}{c}\text { Robust } \\
\text { std. } \\
\text { error }\end{array}$ \\
\hline Ethnic minority (Kinh-Chinese=ref) & 0.78 & $* *$ & 0.07 & 0.82 & $*$ & 0.08 & 0.63 & $* *$ & 0.10 \\
\hline Boy (girl=ref) & 1.15 & $* *$ & 0.05 & 1.18 & *** & 0.06 & 1.48 & $* * *$ & 0.13 \\
\hline Over age 1 (under $1=$ ref) & 1.06 & & 0.06 & 0.99 & & 0.06 & 0.92 & & 0.10 \\
\hline $\begin{array}{l}\text { Having } 3 \text { or more surviving siblings } \\
(2 \text { or fewer siblings }=\text { ref })\end{array}$ & 0.83 & ** & 0.05 & 0.87 & * & 0.06 & 0.83 & $\dagger$ & 0.10 \\
\hline Maternal age & 1.01 & $\dagger$ & 0.004 & 1.00 & & 0.01 & 0.99 & & 0.01 \\
\hline Maternal educational attainment (illit & & & & & & & & & \\
\hline Primary & 1.25 & $* *$ & 0.11 & 1.48 & *** & 0.15 & 1.59 & $* *$ & 0.27 \\
\hline Secondary & 1.00 & & 0.09 & 1.40 & $* *$ & 0.15 & 1.49 & * & 0.27 \\
\hline Geographic location (lowlands=ref) & & & & & & & & & \\
\hline Low mountainous & 0.87 & $\dagger$ & 0.06 & 0.83 & * & 0.07 & 0.93 & & 0.11 \\
\hline High mountainous & 0.88 & $\dagger$ & 0.07 & 0.78 & $* *$ & 0.07 & 0.89 & & 0.12 \\
\hline Less poor $($ poor $=$ ref $)$ & 1.13 & $\dagger$ & 0.08 & 0.93 & & 0.07 & 0.80 & $*$ & 0.09 \\
\hline Number & 3197 & & & 2271 & & & 666 & & \\
\hline
\end{tabular}

Total number $=11,355$

$\dagger$ significant at $\mathrm{p}<0.1, *$ significant at $\mathrm{p}<0.05, * *$ significant at $\mathrm{p}<0.01, * * *$ significant at $\mathrm{p}<0.001$

${ }^{a}$ The reference category for the equation is not sick.

Source: VNHS 2001-2 
Figure 3. Types of parental care-seeking in the event of childhood illness, by ethnicity and household economic status

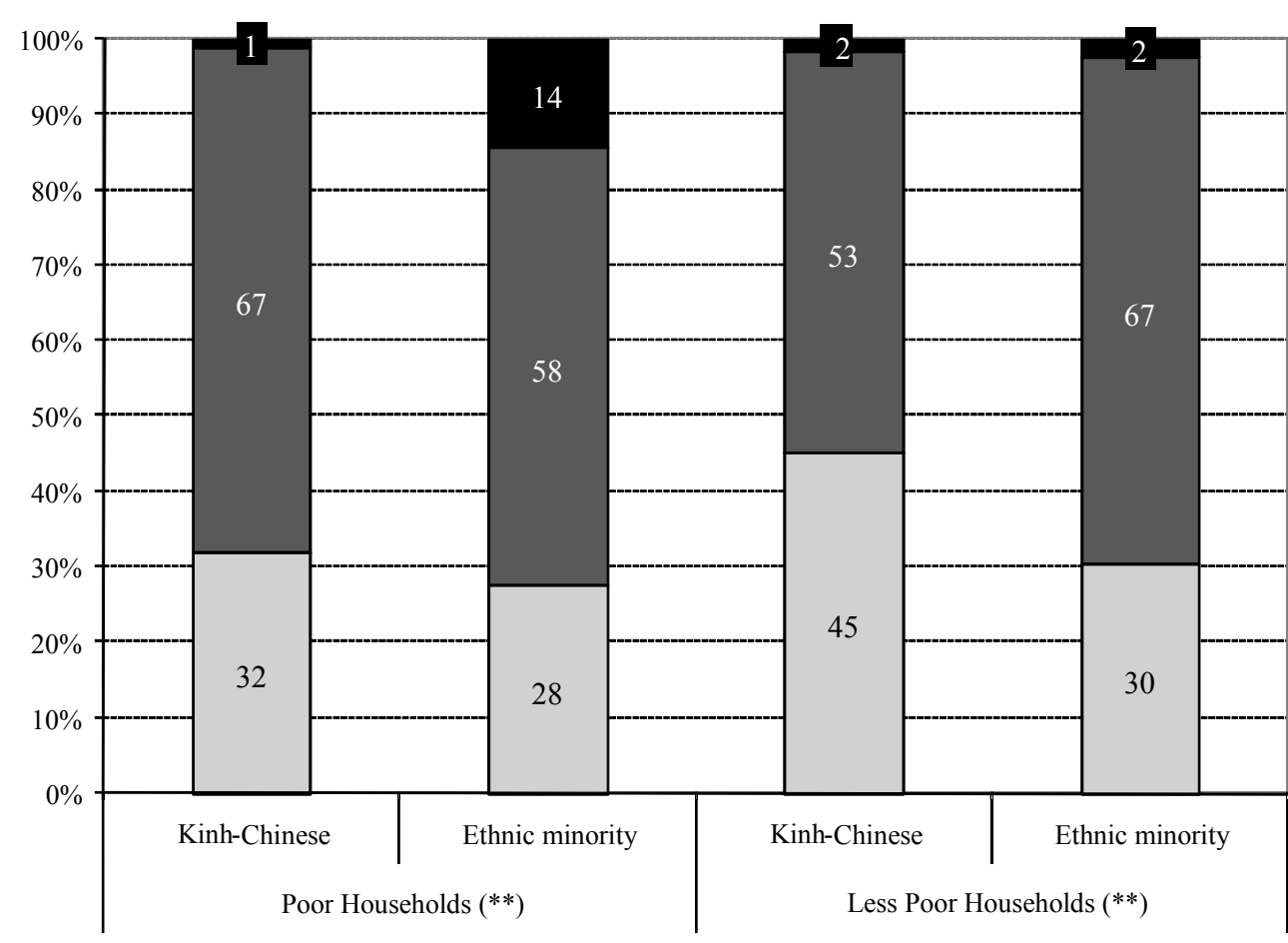

Did not seek any care

$\square$ Self-prescribed care

$\square$ Sought professional consultation

** Difference between Kinh-Chinese and ethnic minority is significant at $\mathrm{p}<0.01 ; \mathrm{n} . \mathrm{s}$. $=$ not significant $\mathrm{p}$-value Note: Results from chi-square tests of significance are reported in parentheses.

Source: VNHS 2001-2. 
Table 3. Maximum-likelihood multinomial logistic regression, incidence of reported illness among children under age 5

\begin{tabular}{|c|c|c|c|c|c|c|}
\hline \multirow{3}{*}{ Child and household characteristics } & \multicolumn{6}{|c|}{ Type of health-seeking ${ }^{a}$} \\
\hline & \multicolumn{3}{|c|}{$\begin{array}{c}\text { Sought professional } \\
\text { consultation }\end{array}$} & \multicolumn{3}{|c|}{ Self-prescribed care } \\
\hline & $\begin{array}{l}\text { Odds } \\
\text { ratio }\end{array}$ & & $\begin{array}{l}\text { Robust } \\
\text { std. } \\
\text { error }\end{array}$ & $\begin{array}{l}\text { Odds } \\
\text { ratio }\end{array}$ & & $\begin{array}{l}\text { Robust } \\
\text { std. } \\
\text { error }\end{array}$ \\
\hline Boy (girl=ref) & 1.01 & & 0.15 & 1.04 & & 0.16 \\
\hline Over age 1 (under $1=$ ref) & 0.64 & $*$ & 0.14 & 0.96 & & 0.20 \\
\hline \multicolumn{7}{|l|}{ Having 3 or more surviving siblings including self } \\
\hline Maternal age & 0.99 & & 0.02 & 0.99 & & 0.01 \\
\hline \multicolumn{7}{|l|}{ Maternal educational attainment (illiterate $=$ ref) } \\
\hline Primary & 1.76 & $*$ & 0.41 & 1.62 & $*$ & 0.35 \\
\hline Secondary & 2.56 & $* * *$ & 0.73 & 2.22 & $* * *$ & 0.61 \\
\hline \multicolumn{7}{|l|}{ Perceived severity (slight illness=ref) } \\
\hline Moderate illness & 3.54 & $* * *$ & 0.64 & 1.20 & & 0.21 \\
\hline Severe illness & 7.77 & $* * *$ & 2.66 & 0.92 & & 0.32 \\
\hline \multicolumn{7}{|l|}{ Ethnicity and geographic location (lowlands $=$ ref) } \\
\hline Kinh-Chinese mountainous & 0.67 & & 0.21 & 1.04 & & 0.32 \\
\hline Minority mountainous & 0.15 & $* * *$ & 0.05 & 0.24 & $* * *$ & 0.07 \\
\hline Less poor (poor=ref) & 0.78 & & 0.23 & 0.48 & $* *$ & 0.13 \\
\hline Exposure to policies (non-exposure $=$ ref) & 0.97 & & 0.66 & 1.14 & & 0.76 \\
\hline \multicolumn{7}{|l|}{ Interaction terms } \\
\hline Exposure to policies $*$ Less poor & 8.51 & $* * *$ & 5.21 & 9.39 & $* * *$ & 5.67 \\
\hline Exposure to policies * Kinh-Chinese mountainous & 0.48 & & 0.42 & 0.35 & & 0.30 \\
\hline Exposure to policies * Minority mountainous & 0.39 & & 0.27 & 0.28 & $\dagger$ & 0.19 \\
\hline Number & 2483 & & & 3447 & & \\
\hline
\end{tabular}

Total number $=6,134$

$\dagger$ significant at $\mathrm{p}<0.1, *$ significant at $\mathrm{p}<0.05, * *$ significant at $\mathrm{p}<0.01, * * *$ significant at $\mathrm{p}<0.001$

${ }^{3}$ The reference category for the equation is not seeking any care.

Source: VNHS 2001-2 


\section{Poverty, Gender, and Youth Working Papers}

If still in print, single copies of up to three working papers from 1989 through 2003 are available free of charge.

Beginning with the 2004 issues, working papers are no longer available in print format. Instead they are distributed electronically. As each new paper is completed, subscribers are notified by e-mail and a link to the paper is provided.

To subscribe to the Poverty, Gender, and Youth working paper e-mail notification list, or to obtain back issues from 1989 to 2003, please send your request to pgywp@popcouncil.org.

PDFs of recent issues are available at www.popcouncil.org/publications/wp/index.html

2007

3 Bussarawan Teerawichitchainan and James F. Phillips, "Ethnic differentials in parental health seeking for childhood illness in Vietnam."

2 Zachary Zimmer, Kim Korinek, John Knodel, and Napaporn Chayovan, "Support by migrants to their elderly parents in rural Cambodia and Thailand: A comparative study."

1 Sharon Ghuman and Cynthia B. Lloyd, "Teacher absence as a factor in gender inequalities in access to primary schooling in rural Pakistan."

\section{Policy Research Division working papers}

2006

219 Cynthia B. Lloyd and Barbara S. Mensch, "Marriage and childbirth as factors in school exit: An analysis of DHS data from sub-Saharan Africa."
218 Ayaga A. Bawah, James F. Phillips, Martin Adjuik, Maya VaughanSmith, Bruce MacLeod, and Fred N. Binka, "The impact of immunization on the association between poverty and child survival: Evidence from Kassena-Nankana District of northern Ghana."

217 Zachary Zimmer, "Poverty, wealth inequality, and health among older adults in rural Cambodia."

216 John Bongaarts, "Late marriage and the HIV epidemic in sub-Saharan Africa."

215 John Bongaarts, "How long will we live?"

214 Zachary Zimmer, Toshiko Kaneda, and Laura Spess, "Urban versus rural mortality among older adults in China."

213 Paul Demeny and Geoffrey McNicoll, "The political demography of the world system, 2000-2050."

212 Monica Grant and Kelly Hallman, "Pregnancy-related school dropout and prior school performance in South Africa." 
211 Kelly Hallman, Sara Peracca, Jennifer Catino, and Marta Julia Ruiz, "Multiple disadvantages of Mayan females: The effect of gender, ethnicity, poverty, and residence on education in Guatemala."

210 Geoffrey McNicoll, "Policy lessons of the East Asian demographic transition."

209 Cynthia B. Lloyd, Cem Mete, and Monica J. Grant, "The implications of changing educational and family circumstances for children's grade progression in rural Pakistan: 19972004."

2005

208 James F. Phillips, Ayaga A. Bawah, and Fred N. Binka, "Accelerating reproductive and child health program development: The Navrongo Initiative in Ghana."

207 John Bongaarts and Griffith Feeney, "The quantum and tempo of lifecycle events."

206 Barbara S. Mensch, Monica J. Grant, and Ann K. Blanc, "The changing context of sexual initiation in subSaharan Africa.”

205 Geoffrey McNicoll, "Population and sustainability."

204 John Bongaarts, "The causes of stalling fertility transitions."

203 Ayaga A. Bawah and Fred N. Binka, "How many years of life could be saved if malaria were eliminated from a hyperendemic area of northern Ghana?"

202 Barbara S. Mensch, Susheela Singh, and John B. Casterline, "Trends in the timing of first marriage among men and women in the developing world."
Zachary Zimmer, "Active life expectancy and functional limitations among older Cambodians: Results from a 2004 survey."

200 Brian Wells Pence, Philomena Nyarko, James F. Phillips, and Cornelius Debpuur, "The effect of community nurses and health volunteers on child mortality: The Navrongo Community Health and Family Planning Project."

199 Zachary Zimmer, Linda G. Martin, Mary Beth Ofstedal, and Yi-Li Chuang, "Education of adult children and mortality of their elderly parents in Taiwan."

198 Mian Bazle Hossain, James F. Phillips, and Thomas K. LeGrand, "The impact of childhood mortality on fertility in six rural thanas of Bangladesh.”

197 Kristine R. Baker, Mary Beth Ofstedal, Zachary Zimmer, Zhe Tang, and Yi-Li Chuang, "Reciprocal effects of health and economic wellbeing among older adults in Taiwan and Beijing."

196 Mark R. Montgomery and Paul C. Hewett, "Poverty and children's schooling in urban and rural Senegal." 